\title{
Effects of metacognitive scaffolding on students' performance and confidence judgments in simulation-based inquiry
}

\author{
Hong-Syuan Wang $\odot,{ }^{1}$ Sufen Chen $\odot,{ }^{2,3, *}$ and Miao-Hsuan Yen ${ }^{1}$ \\ ${ }^{1}$ Graduate Institute of Science Education, National Taiwan Normal University, Taipei 11677, Taiwan \\ ${ }^{2}$ Graduate Institute of Digital Learning and Education, National Taiwan University of Science and \\ Technology, Taipei 10607, Taiwan \\ ${ }^{3}$ Optentia Research Focus Area, North-West University, Vanderbijlpark 1900, South Africa
}

(Received 10 March 2021; accepted 17 June 2021; published 13 August 2021)

\begin{abstract}
This study aims to examine the effectiveness of metacognitive scaffolding in different inquiry tasks related to optics. Two high school classes participated in this study. One class, the treatment group $(n=33)$, which integrated metacognitive prompts into the simulation-based inquiry, was compared to the other class, the control group $(n=34)$, which received only simulation-based inquiry. Students' conceptual understanding, integrated science process skills, confidence judgment, and inquiry performance were measured using a multiple-choice pretest and post-test and worksheets. The results show that the students' conceptual understanding and confidence judgments on conceptual understanding in both groups significantly increased from the pretest to the post-test. Incorporating metacognitive scaffolds into inquirybased learning better facilitated the improvement of integrated science process skills as well as the confidence judgment on the process skills, especially in the more complex tasks. The metacognitive scaffolding could be applied to various inquiry activities to enhance students' control of variables, data interpretation, and graph comprehension.
\end{abstract}

DOI: 10.1103/PhysRevPhysEducRes.17.020108

\section{INTRODUCTION}

The last few decades have seen growing importance placed on inquiry-based learning (IBL) in science education [1-3]. Students are encouraged to construct, extend, and refine their science knowledge through authentic scientific practices [4,5]. With the increasing usage of computer technology, many IBL activities are built upon computer simulations to promote science learning through visualization and interactivity with dynamic models of scientific phenomena [6]. More specifically, the unique affordances of computer simulations, such as visualizing abstract constructs, displaying dynamic processes, and incorporating multiple representations, could enrich students' inquiry experience and facilitate deeper conceptual understanding [7-9].

Optics learning, including various abstract representations (e.g., light rays, wave front, etc.), is challenging for students. Several studies have noted that most students from elementary school to university have difficulties

\footnotetext{
*Corresponding author. sufchen@mail.ntust.edu.tw

Published by the American Physical Society under the terms of the Creative Commons Attribution 4.0 International license. Further distribution of this work must maintain attribution to the author(s) and the published article's title, journal citation, and DOI.
}

understanding various concepts of optics, such as vision, image formation, interference, and diffraction [10-13]. In the field of geometric optics, the ray model has been developed as an important tool to understand image formation, whereas in wave optics, the wave model is used to explain wavelike behaviors of light. Since many of the critical features of these two models are not directly observable, the abstract representations may result in misconceptions [14-16]. Furthermore, lack of qualitative understanding of these models may lead to incorrect application of geometric optics or wave optics in a given situation [14]. To overcome these learning difficulties, simulation-based inquiry is used to help students enhance conceptual understanding of optics and acquire science process skills (SPS). However, inquiry is a multifaceted activity in which students struggle to select, organize, and integrate relevant information [17]. Metacognition is needed to conduct a successful inquiry $[18,19]$. Many students have difficulties regulating their learning process automatically if external guidance or support is absent [20], which is why metacognitive scaffolding is often called into play during the learning process [21,22]. Metacognitive scaffolding assists students in planning effective learning strategies, monitoring their learning processes, and assessing their state of understanding.

SPS can be broadly divided into two levels, namely, basic and integrated [23]. Basic SPS consists of observing, inferring, measuring, communicating, classifying, and 
predicting, while integrated SPS include logical thinking, planning, and synthesizing, such as controlling variables, defining operationally, hypothesizing, experimenting, interpreting data, and formulating models. As Brotherton and Preece [24] pointed out, the mastery of SPS is tied closely with Piaget's cognitive development. More specifically, students in the concrete operational stage can use basic SPS well, while students in the formal operational stage can implement integrated SPS. The current study caters to integrated SPS for high school students.

While several studies have demonstrated the positive effects of metacognitive strategies on conceptual understanding and the development of SPS in IBL [25-27], there have been few attempts to examine the relationship between the role of metacognitive scaffolding and the complexity of inquiry tasks. Additionally, little research has been done on the effect of metacognitive scaffolding on students' confidence judgments in conceptual understanding and SPS. The central purposes of this study were to ascertain the effects of metacognitive scaffolding on students' performance and confidence judgments in simulation-based inquiry, and to examine the relationship between the role of metacognitive scaffolding and inquiry tasks with different degrees of complexity.

\section{RESEARCH QUESTIONS}

To investigate the effects of metacognitive scaffolding on students' learning outcomes and confidence judgments, and to understand the role of metacognitive scaffolding in different types of inquiry tasks, the main research questions are as follows:

1. What are the effects of metacognitive scaffolding on students' conceptual understanding and confidence judgments on conceptual understanding?

2. What are the effects of metacognitive scaffolding on students' integrated SPS and confidence judgments on integrated SPS?

3. How does the metacognitive scaffolding affect students' performance on inquiry tasks with different degrees of complexity?

\section{THEORETICAL BACKGROUND}

\section{A. Inquiry-based learning}

According to the National Science Education Standards (NSES), inquiry-based instruction provides students with opportunities to explore methods and practices similar to those required for scientific research. When students engage in IBL activities, they make observations, pose testable questions, plan, design, and conduct the investigation, collect and analyze data with mathematical and computational tools, formulate explanations, develop scientific models, justify different kinds of claims with evidence, and communicate and reflect on the investigation $[3,28]$. Such learning approaches enable students to use
SPS to construct scientific knowledge and convert from knowledge consumers to knowledge constructors [29].

IBL is highly valued, yet not easy to carry out in reality. Over the past few decades, many instructional approaches have been developed to make scientific inquiry accessible to students. The multifaceted activity is often unpacked into smaller and interrelated phases that guide students to practice. For example, the inquiry cycle lists five inquiry phases: question, predict, experiment, model, and apply [30]. This inquiry process could go through many cycles. White and Frederiksen [30] suggested that students reflect on both the restrictions and the deficiencies of the results before the beginning of a new cycle. Similarly, Krajcik et al. [31] proposed the investigation web, including five aspects of inquiry: asking questions, designing investigations and planning procedures, constructing apparatus and carrying out investigations, analyzing data and drawing conclusions, and collaborating and presenting findings. Compared with the traditional stepwise scientific method, the configuration of the investigation web emphasizes that inquiry is not a linear process but rather a complex interactive network. Students repeatedly alter procedures until a problem is solved or the best answer is found.

Despite the fact that different researchers use slightly different terms, the essential components for comprehensive IBL include questioning and hypothesis generation, planning, experimentation, analysis, conclusion, communication, and reflection [32,33]. These phases are not in a fixed chronological order, and there are multiple possible pathways to conduct inquiry. In the questioning and hypothesis generation phase, students come up with research questions that are testable and predict possible outcomes to formulate hypotheses. In the planning phase, students develop a list of feasible strategies to examine which of their competing hypotheses is accurate. They identify the variables related to their research questions and determine how to operationalize and control relevant variables in the experiments. In the experimentation phase, students construct apparatus and carry out their investigation, including making systematic observations, taking measurements and recording data. After conducting their experiments, students contrast multiple data sources, look for the empirical relationships among the variables, and present data as evidence in the analysis phase. Mathematical and computational tools may be used for displaying physical variables in charts or graphs and generalizing their relationships. In the conclusion phase, students engage in scientific argumentation and establish evidence-based explanations. They coordinate evidence and theory to build or refine scientific models. Regarding communication, students express and discuss their ideas and findings to peers in a variety of forms, for example, verbal description, text, tables, diagrams, graphs, and equations. At the same time, they receive comments or suggestions from others. Concerning reflection, students evaluate and critique what they have 
learned and seek to improve their IBL. It has to be stressed that communication and reflection are not restricted to any particular phases, but occur throughout the whole inquiry process [3]. On the whole, these core features of scientific inquiry help students practice SPS and facilitate the understanding of content knowledge.

\section{B. Metacognition in inquiry-based learning}

Metacognition often refers to higher-level cognition that oversees and controls one's cognitive processing [34]. Metacognition and its implications for IBL have become one of the more intriguing issues in science education research [35]. IBL matches with constructivism which considers that ideas and knowledge might be developed and constructed by students [36]. Yet the knowledge construction does not come easily. A substantial body of research has shown underlying difficulties that students face in IBL. For example, students often fail to focus on the related variables that should be analyzed [37], misinterpret or neglect the data that go against their existing models, and are hardly aware that their wrong explanations would lead to wrong conclusions $[38,39]$. Simply stated, many students do not automatically monitor and regulate their learning process [40].

Furthermore, technology-enhanced IBL offers multiple representations and bountiful information, but may also complicate the learning [41]. Metacognitive skills are needed to help students process information and frame inquiry activities in complex learning environments [18]. Three crucial metacognitive skills are (a) planning the learning goals and selecting effective strategies, (b) monitoring the progress towards the learning goals, and (c) evaluating the outcomes and efficiency of learning [42]. Metacognitive planning enables students to set goals and sub-goals hierarchically and allocate available resources to perform IBL tasks [43]. In the process of executing the strategic plans, students monitor what they are doing and confirm whether they are making progress to reach the goals and subgoals [44]. Finally, accurately making confidence judgments on one's own performance of a specific task is closely related to students' academic achievements [45]. Underconfident students have been found to express lower science attitudes which thus constrained their learning [46]. Overconfident students tend to stop studying before they really understand what they have learned [47]. Specifically, students with confidence bias are prone to poor self-regulation and further learning.

Several studies have suggested the benefit of metacognitive scaffolding in IBL. It was found that students' content knowledge, inquiry performance, and self-regulation were improved when metacognitive instruction was provided $[25,26,48]$. Since prompts are the most common instructional practice in the literature [35], reflective prompts are used as metacognitive scaffolding in this paper. These reflective prompts are presented in students' worksheets, with the aim of triggering students' metacognitive skills and facilitating their inquiry performance.

\section{METHODS}

\section{A. Participants}

The participants in this study were 6711 th-grade students (aged 16-17) in two classes at an urban high school in Taiwan. One class was assigned as the treatment group $(n=33)$ and the other was the control group $(n=34)$. Both groups learned through the simulation-based inquiry. For the treatment group, the inquiry was integrated with metacognitive scaffolding, while it was not for the control group. The percentage of participants in the two groups did not differ by gender, $\chi^{2}(1, N=67)=1.21, p=0.27$.

\section{B. Procedure}

In this quasiexperimental study, the learning activities were carried out in eight lessons (Fig. 1). Before and after the interventions, both groups performed paper-and-pencil tests of the optics concepts and the integrated science skills along with the confidence judgments on both tests. The learning activities were built upon computer-supported learning environments to provide insights into the underlying mechanisms of optics phenomena. Two of them were inquiry based with different levels of complexity, namely, simple and emulation tasks. The major difference was the number of variables and the experimental errors involved. For the simple task, students manipulated a single independent variable in an ideal condition without experimental errors. For the emulation task, students had to decide what variables to control and manipulate among several possible variables, and the experimental data included some errors as in an authentic physical experiment. Students carried out the tasks using worksheets. Metacognitive scaffolding designed to facilitate integrated science skills was provided for the treatment group. The two inquiry practices with metacognitive scaffolding were piloted with 2412 th graders. Some adjustments were made regarding the instructions and task structure based on the pilot outcomes. Students' responses on worksheets of the inquiry tasks were collected and graded to represent their inquiry performance.

\section{Measuring instruments}

\section{Optics conceptual test}

A test of optics concepts was used in the study to assess students' optics conceptual understanding. In keeping with the curriculum guidelines [28], the test was designed to assess six concepts, namely, image formation in a plane mirror, image formation from a converging lens, the principle of superposition for waves, a two-point source interference pattern, diffraction by a narrow slit, and vision. The complete test is shown in the Supplemental Material Ref. [49]. The test consisted of 15 two-tier multiple 
$\underline{\text { Learning activities }}$

Data collection procedures

\begin{tabular}{|c|c|}
\hline Pretests \\
Optics Conceptual Test \\
Science Skills Test \\
Confidence judgments
\end{tabular}

\section{Lesson 2-4: Simulation-based simple inquiry task \\ (metacognitive scaffolding for the treatment group only) \\ Image formation by a thin converging lens \\ Inquiry performance \\ assessments}

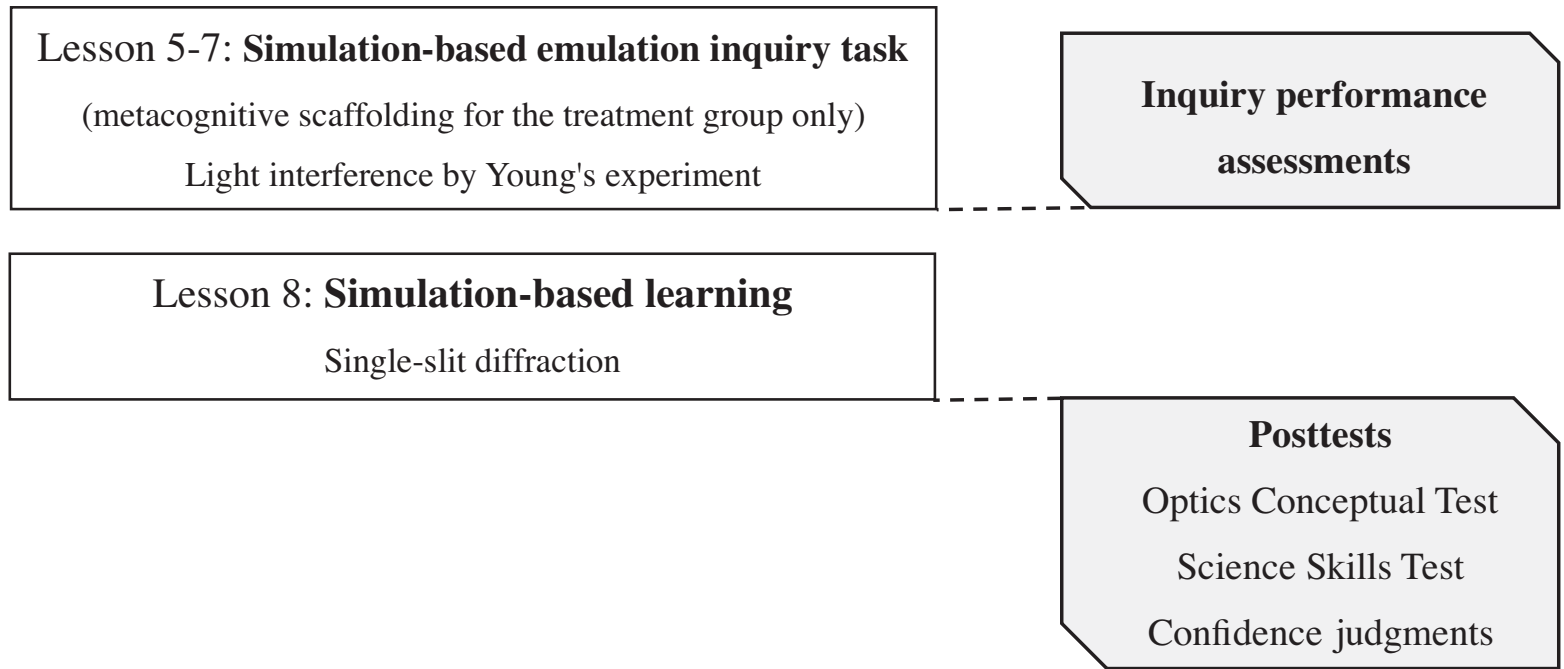

FIG. 1. Learning activities and data-collection procedures.

questions which were derived from the literature $[14,15,50,51]$, the textbook exercises, and the General Scholastic Ability Test of Taiwan. Students had to choose an answer to a question in the first tier, followed by a reason for their chosen answer in the second tier. An opportunity was also provided for students to give their own ideas in case none of the statements fitted their understanding. If students' responses to both the first- and second-tier questions were correct, then 1 point was gained, otherwise 0 was scored. The test items were reviewed by three high school physics teachers to confirm the content validity and face validity of the test. The Cronbach's $\alpha$ coefficient was 0.75 , which was considered moderately reliable [52].

\section{Integrated science process skills test}

SPS are major learning objectives in IBL $[53,54]$. The current study was conducted at high school level and therefore focused on the integrated SPS, especially the control of variables, data interpretation, and the use of graphs to represent data. First, as Chen and Klahr [55] pointed out, the use of the control of variables strategy is key to making valid inferences from the outcomes of unconfounded experiments. Second, the data interpretation capability is fundamental for drawing justified conclusions [56]. Students should make meaning out of collected data to reach appropriate conclusions and further synthesize new knowledge. Third, graphs play a large role in comprehending and presenting data [57]. Students should be able to read graphs to identify the relations between variables and use the suitable graphical representation to support their arguments.

The Integrated Science Process Skills Test was developed to assess students' integrated SPS including the control of variables strategy, data interpretation, and graph comprehension. The instrument was comprised of three 
- In the process of data analysis, which of the following statements can correctly describe the functional relationship between the independent variables (IV) and dependent variables (DV)?

(a) Two variables are proportional.

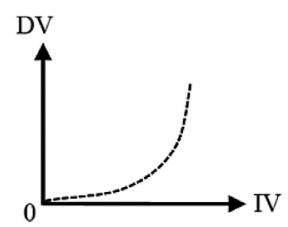

(c) Two variables are proportional.

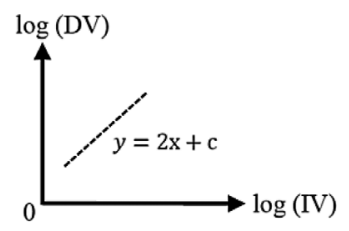

(b) Two variables are inversely proportional.

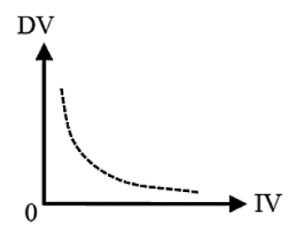

(d) Two variables are inversely proportional.

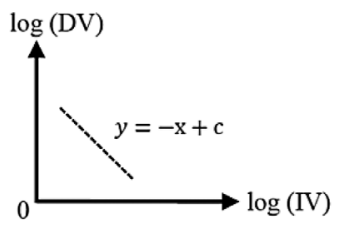

How confident are you with your answer in the above question?
(a) Strongly unconfident
(b) unconfident
(c) Confident
(d) Strongly confident

FIG. 2. An example question of the Integrated Science Process Skills Test and the related confidence judgments.

questions that were derived from the textbook exercises and the panel discussion of three experienced physics teachers. The first question examined the ability to use the control of variables strategy. Students identified whether the four variables provided in the context affect the related scientific phenomena. Each correct identification of a variable counted as 1 point, adding up to 4 . The second question was related to data interpretation. Students determined whether the four interpretations were correct based on the evidence provided in the context. The correct response to each interpretation was scored 1 , adding up to 4 points. Finally, regarding graph comprehension, students were asked to predict the correct functional relationship between the independent and dependent variables based on the trends of the data shown in the graph (see Fig. 2 for the example question), which was credited with another 4 points. The total score of the Integrated Science Process Skills Test ranged from 0 to 12 . The Cronbach's $\alpha$ coefficient was 0.67 . The test was also reviewed by three high school physics teachers to confirm the content and face validity.

\section{Confidence judgments}

Metacognitive monitoring plays a large role in metacognitive processing and has a significant impact on students' learning [47,58]. According to Kleitman and Moscrop [59], measures of task-specific confidence have been used successfully to assess metacognitive monitoring processes. In our research, students make a confidence judgment about their performance after completing each test item of the conceptual test including both tiers and the SPS tests, as shown in Fig. 2. The monitoring accuracy, namely, absolute accuracy index, was calculated by the discrepancy between a confidence judgment and performance on a relevant question [60]. The equation for computing absolute accuracy is given by

$$
\text { Absolute Accuracy Index }=\frac{1}{N} \sum_{i=1}^{N}\left(c_{i}-p_{i}\right)^{2},
$$

where $c_{i}, p_{i}$, and $N$ refer to a confidence rating, a performance score, and the total number of items. Students rate their confidence on an ordinal scale with a four-point interval that ranges from 0 (i.e., strongly unconfident) to 1 (i.e., strongly confident) with intervals of 0.33. Performance scores are the correctness percentage from 0 (i.e., incorrect) to 1 (i.e., correct). The absolute accuracy index ranges from 0 to 1 , where a score of 0 corresponds to perfect accuracy and a score of 1 corresponds to inaccuracy.

\section{Inquiry performance}

The participants conducted two IBL in optics. Students' responses on the worksheets were used to assess their inquiry performance. With reference to policy reports and curriculum guidelines [28] and related research on scientific inquiry assessment [61-63], a scoring framework was 
TABLE I. A scoring framework of the inquiry performance assessments.

\begin{tabular}{|c|c|c|c|c|}
\hline Inquiry phase & Inquiry abilities & Skills level & Simple task & Emulation task \\
\hline \multirow[t]{2}{*}{ Planning } & - Observing scientific phenomena & Basic & $0-5$ & $0-2$ \\
\hline & - Identifying variables that can affect experimental outcomes & Integrated & $0-3$ & $0-4$ \\
\hline Experimentation & $\begin{array}{l}\text { - Measuring and recording data in tables } \\
\text { - data are recorded in appropriate units } \\
\text { - collect enough data for analysis }\end{array}$ & Basic & $0-3$ & $0-3$ \\
\hline \multirow[t]{2}{*}{ Analysis } & $\begin{array}{l}\text { - Constructing graphs of the data } \\
\text { - numbers are linearly and evenly spread on axes } \\
\text { all measurements fall into available space within the } \\
\text { coordinate axes }\end{array}$ & Basic & $0-2$ & $0-2$ \\
\hline & - Transforming data into an appropriate form & Integrated & $0-2$ & $0-2$ \\
\hline \multirow[t]{2}{*}{ Conclusion } & $\begin{array}{l}\text { - Drawing appropriate conclusions from evidence } \\
\text { - describe the qualitative relationship between variables } \\
\text { - use a formula to represent the relationship between variables } \\
\text { - construct the best-fit trend line using statistical methods } \\
\text { - describe the validity and limitations of the experimental outcomes }\end{array}$ & Integrated & $0-5$ & $0-6$ \\
\hline & Maximum scores & & 20 & 19 \\
\hline
\end{tabular}

constructed for each inquiry phase (Table I). The different inquiry abilities are categorized as basic skills and integrated skills. In order to reach a high quality of reliability, approximately one-third of the worksheets were rated by two independent raters. The interrater reliability of the rubrics was 0.93 . Disagreements were discussed by the two raters after the reliability analysis, and the worksheets were rated according to mutual agreement.

\section{Intervention}

The interventions focused on image formation and wave optics. The students used computer simulations for all learning activities. The activities started from reflection in a plane mirror to diffraction of light. Regarding image formation by mirrors and lenses, the luminous ray model (LRM) in Fig. 3 was used to help students have a better understanding of the concept of an image [64]. LRM

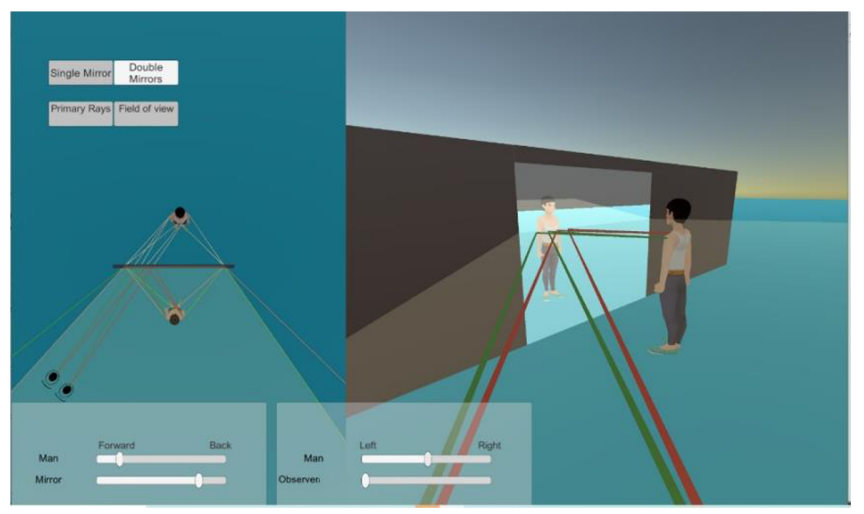

FIG. 3. The luminous ray model presented by image formation in a plane mirror. differed from the conventional model by showing the whole field of view, rather than two or three primary light rays only, to help students understand from where an image is viewable.

In Lesson 1, the teacher introduced the law and types of reflection. Students practiced the exercises in the textbook using computer simulation which was developed using UNITY (Fig. 3). In lessons 2-4, the students used computer simulation as illustrated in Fig. 4(a) to explore image formation by a converging lens. The simulation was developed using FLASH. The students observed scientific phenomena and identified variables operationally to collect meaningful data. For example, they might manipulate the position of an object to observe the position and the height of its image. Based on the empirical relationships illustrated in the graphs, students drew conclusions about the thin lens equation and the lateral magnification. Another computer simulation in Fig. 4(b) supported by the Physics Education Technology (PhET) developed by the University of Colorado was used to understand the concept of interference in lessons 5-7. The students measured the width of the central bright band on the screen and examined what and how various factors affect the width. Like authentic physical experiments, they had to handle some experimental errors, transform the results into graphs, find the empirical relationships among the variables, and coordinate their findings from multiple investigations to obtain Young's equation. In lesson 8, the teacher introduced the single-slit diffraction. The students practiced textbook exercises using PhET simulations.

As Kruit et al. [61] pointed out, analyzing data and presenting it as evidence to draw appropriate conclusions seem to be more difficult for students in IBL. The literature offers a number of inspiring examples to help students 


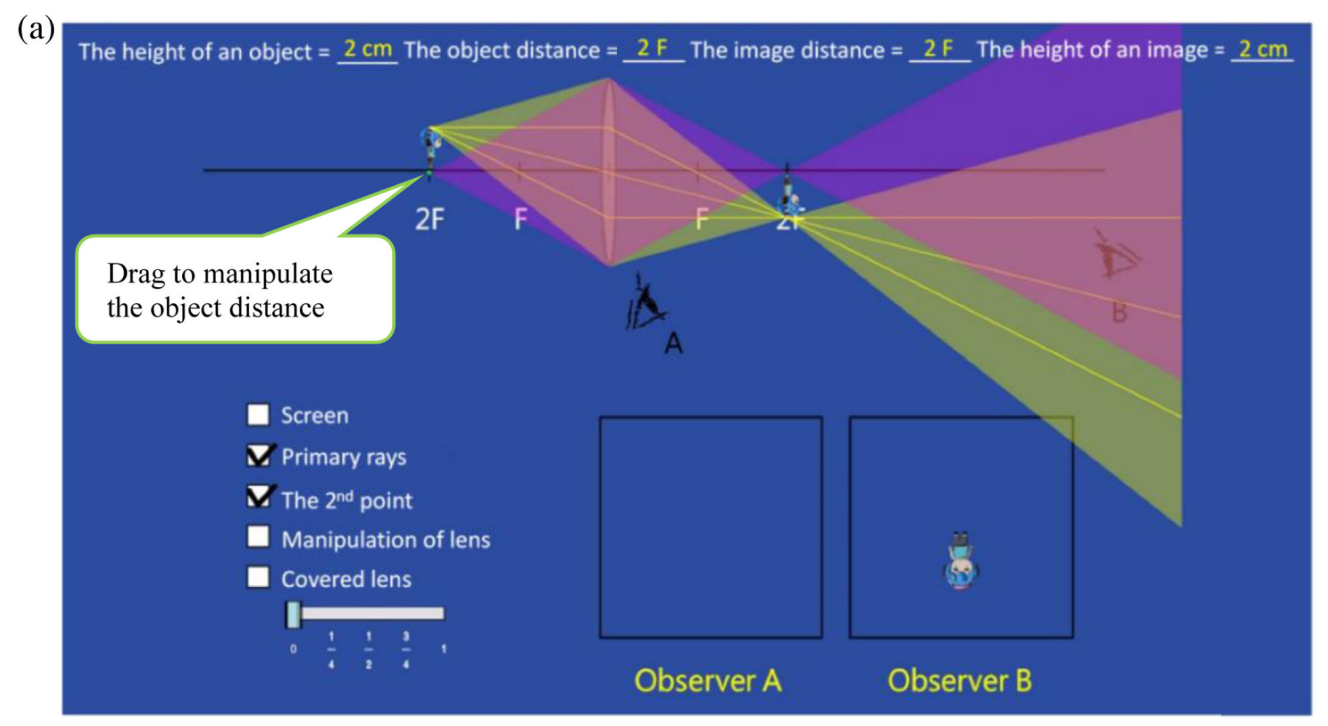

(b)

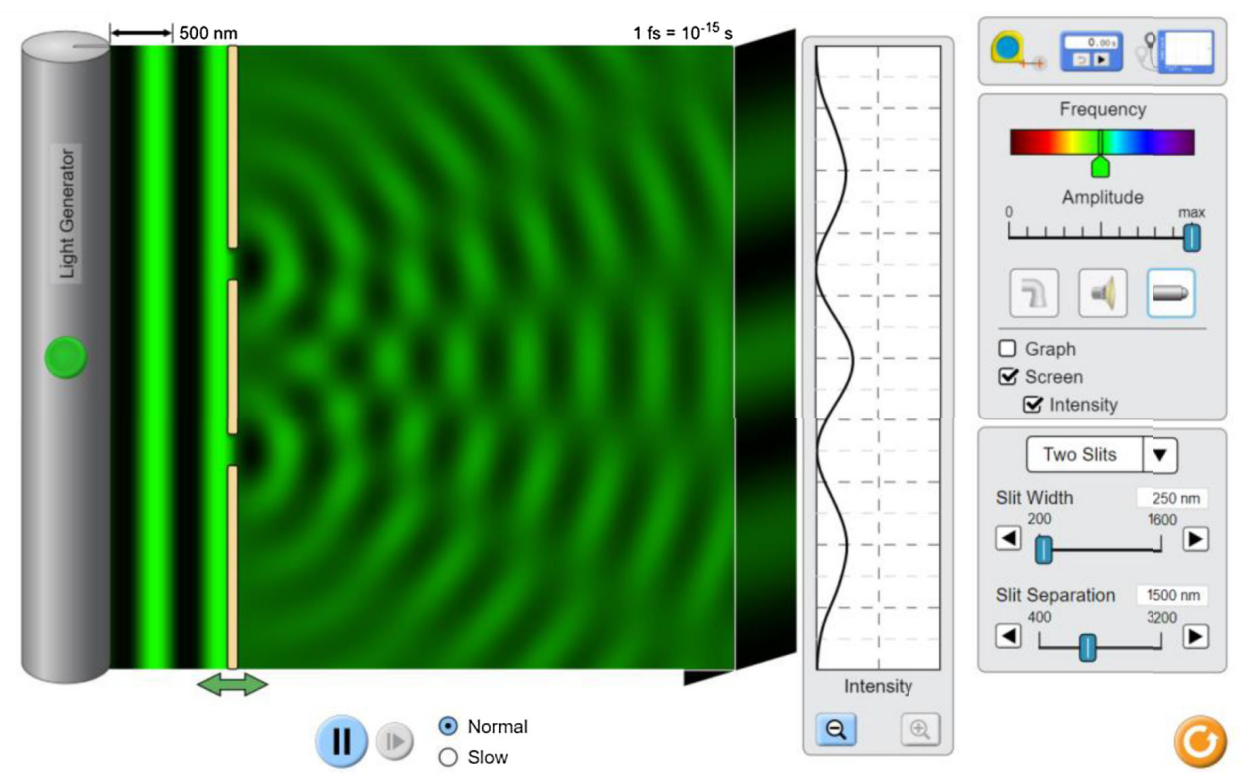

FIG. 4. Computer simulations in (a) image formation by a thin converging lens and (b) Young's experiment using PhET.

monitor the analyzing procedures and justify their arguments [27,65-68]. To overcome their learning difficulties, some metacognitive prompts were added to the analysis and conclusion phases of IBL in the treatment group. Figure 5 shows an example of student's worksheets and the metacognitive prompts used for scaffolding. The scaffolding for the analysis phase was framed in the form of a checklist: (i) Are the variables being analyzed related to the research question? $\square$ Yes $\square$ No, and (ii) Are my data organized to clearly illustrate my findings? $\square$ Yes $\square$ No. The scaffolding for the conclusion phase was in openended and checklist formats: (i) Based on what reasons did I draw such conclusions?, and (ii) Do I have enough evidence to support my conclusions? $\square$ Yes $\square$ No. These prompts reminded students to think carefully about which variables they should focus on and to monitor the consistency between their explanations and the data. The prompts were not scored.

\section{E. Data analysis}

Research question 1 investigated the effects of metacognitive scaffolding by comparing the performance on the paper and pencil tests of the optics conceptual test and confidence judgments. Research question 2 changed the focus from conceptual understanding to integrated SPS. For these two questions, pairwised $t$ tests were used to examine the progress of each group from pretest to post-test. Analysis of covariance (ANCOVA), using the scores of the pretest as the covariate, was carried out to compare the differences between the treatment group and the control group. Research question 3 aimed to examine the effects of 
1-2. Collect data, and record them in Table I.

Table I. Results for experiment I.

\begin{tabular}{|l|l|l|l|l|l|l|l|l|l|l|l|}
\hline the central bright band & & & & & & & & & & & \\
\hline & & & & & & & & & & & \\
\hline & & & & & & & & & & & \\
\hline
\end{tabular}

1-3.Plot the relevant data in the Fig. 1.

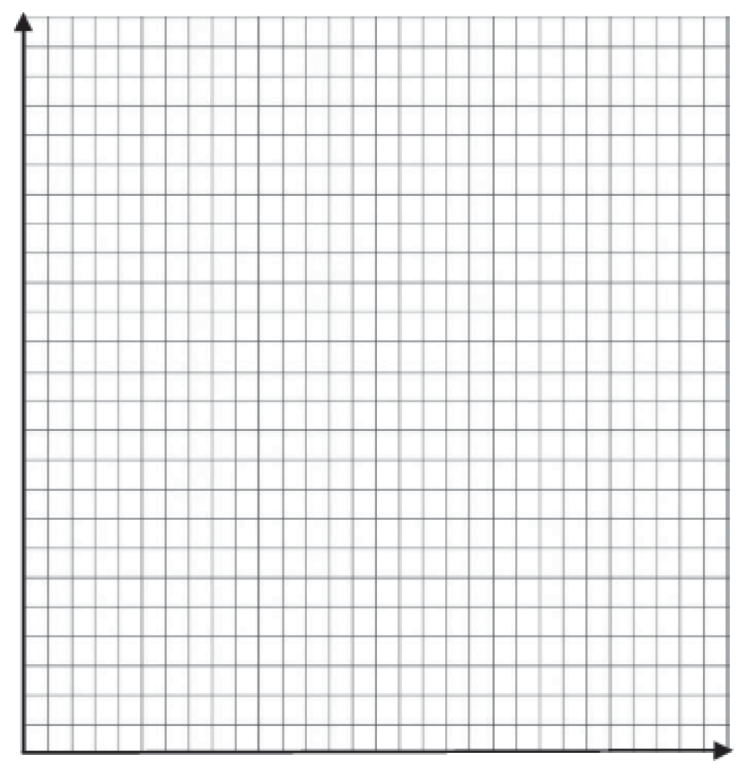

Fig. 1

check:

(1) Are the variables being analyzed related to my research question? ( $\square$ Yes $\square$ No)

(2) Are my data organized to clearly illustrate my findings? ( $\square$ Yes $\square$ No)

1-4. Please describe the mathematical relationship between these variables. Based on what reasons did I draw such conclusions?

Mathematical relationship :

Reasons :

check: Do I have enough evidence to support my conclusions? ( $\square$ Yes $\square$ No)

FIG. 5. An example of an inquiry worksheet and the metacognitive prompts used for scaffolding. 
metacognitive scaffolding on the inquiry tasks with different degrees of complexity. Since the scores of basic SPS and integrated SPS are different in the two IBL worksheets, students' raw scores were divided by the maximum score of basic SPS and integrated SPS to obtain the percentage of correctness. Repeated measured ANOVA was used to identify any differences between the two groups.

\section{RESULTS}

\section{A. Optics conceptual test}

The mean scores of each group in the pre- and postconceptual tests are displayed in Table II. The paired sample $t$ tests showed $p<0.001$ for both groups. The results suggested that the two learning approaches could improve students' understanding of optics concepts. The effect sizes were both large. Furthermore, the one-way ANCOVA using pretest scores as the covariate found no significant difference between the two groups, $F(1,64)=2.03, p=0.16$. This result indicated that students' conceptual understanding was not considerably affected by the introduction of the metacognitive scaffolding.

\section{B. Confidence judgments of the optics conceptual test}

Table III shows the absolute accuracy of confidence judgments on conceptual understanding. The higher the value, the less accurate the judgment. Paired sample $t$ tests indicated a significant difference between the means of the pre- and postconfidence judgments of conceptual understanding for the two groups. The results suggested that the two learning approaches could improve students' metacognitive monitoring of conceptual understanding. The effect sizes were large for both groups. Moreover, the one-way ANCOVA using pretest scores as the covariate indicated that the difference between the two groups was not significant, $F(1,64)=0.06, p=0.81$. The result showed that the introduction of metacognitive scaffolding

TABLE II. Results of the paired-sample $t$ tests for the Optics Conceptual Test.

\begin{tabular}{lcccccc}
\hline \hline & & Pretest & Post-test & & \multicolumn{2}{c}{ Cohen's } \\
Group & $n$ & $M(S D)$ & $M(S D)$ & $t$ & $p$ & $d$ \\
\hline Treatment & 33 & $5.39(1.85)$ & $6.97(2.16)$ & $4.46<0.001$ & 1.55 \\
Control & 34 & $4.74(1.81)$ & $7.24(1.71)$ & $8.11<0.001$ & 2.78 \\
\hline \hline
\end{tabular}

TABLE III. Results of the paired-sample $t$ tests for confidence judgments of conceptual understanding.

\begin{tabular}{lcccccc}
\hline \hline & & Pretest & Post-test & & \multicolumn{2}{c}{ Cohen's } \\
Group & $n$ & $M(S D)$ & $M(S D)$ & $t$ & $p$ & $d$ \\
\hline Treatment & 33 & $0.28(0.10)$ & $0.22(0.07)$ & $-4.39<0.001$ & 1.53 \\
Control & 34 & $0.28(0.05)$ & $0.22(0.06)$ & $-4.80<0.001$ & 1.65 \\
\hline \hline
\end{tabular}

had no considerable impact on students' metacognitive monitoring of conceptual understanding.

\section{Integrated science process skills test}

The mean scores of each group in the pre- and postscience skills tests are presented in Table IV. The paired sample $t$ tests showed only significant improvement for the treatment group with a large effect size. Furthermore, the one-way ANCOVA using pretest scores as the covariate indicated that there was a significant difference between the two groups, $F(1,64)=15.15, p<0.001, \eta_{p}^{2}=0.19$. The results revealed that the introduction of metacognitive scaffolding is beneficial for improving students' integrated SPS.

\section{Confidence judgments of the integrated SPS test}

Table V presents the absolute accuracy of confidence judgments on integrated SPS. Paired sample $t$ tests showed a significant higher accuracy from the pre- to the postconfidence judgments of integrated SPS for the treatment group with a large effect size. Furthermore, the one-way ANCOVA using pretest scores as the covariate showed a significant effect of metacognitive scaffolding, $F(1,64)=7.71$, $p=0.007, \eta_{p}^{2}=0.11$. In other words, although the introduction of metacognitive scaffolding was not particularly beneficial to students' metacognitive monitoring of conceptual understanding, it improved their judgments on integrated SPS.

\section{E. Inquiry performance}

The inquiry tasks required both basic and integrated SPS. The latter were supported by metacognitive scaffolding in the treatment group. Students' responses on the worksheets were evaluated to examine their inquiry performance on tasks with different levels of complexity. Table VI and Fig. 6 display the mean score and standard deviation of the

TABLE IV. Results of the paired-sample $t$ tests for Integrated SPS Test.

\begin{tabular}{lcccccc}
\hline \hline & & Pretest & Post-test & & \multicolumn{2}{c}{ Cohen's } \\
Group & $n$ & $M(S D)$ & $M(S D)$ & $t$ & $p$ & $d$ \\
\hline Treatment & 33 & $7.42(1.86)$ & $8.94(2.06)$ & 3.14 & 0.004 & 1.09 \\
Control & 34 & $6.71(1.77)$ & $7.00(1.86)$ & 0.69 & 0.49 & 0.24 \\
\hline \hline
\end{tabular}

TABLE V. Results of the paired-sample $t$ tests for confidence judgments of integrated SPS.

\begin{tabular}{lccccccc}
\hline \hline & & Pretest & Post-test & & \multicolumn{2}{c}{ Cohen's } \\
Group & $n$ & $M(S D)$ & $M(S D)$ & $t$ & $p$ & $d$ \\
\hline Treatment & 33 & $0.18(0.12)$ & $0.11(0.06)$ & -3.56 & 0.001 & 1.24 \\
Control & 34 & $0.15(0.11)$ & $0.18(0.14)$ & 0.93 & 0.36 & 0.32 \\
\hline \hline
\end{tabular}



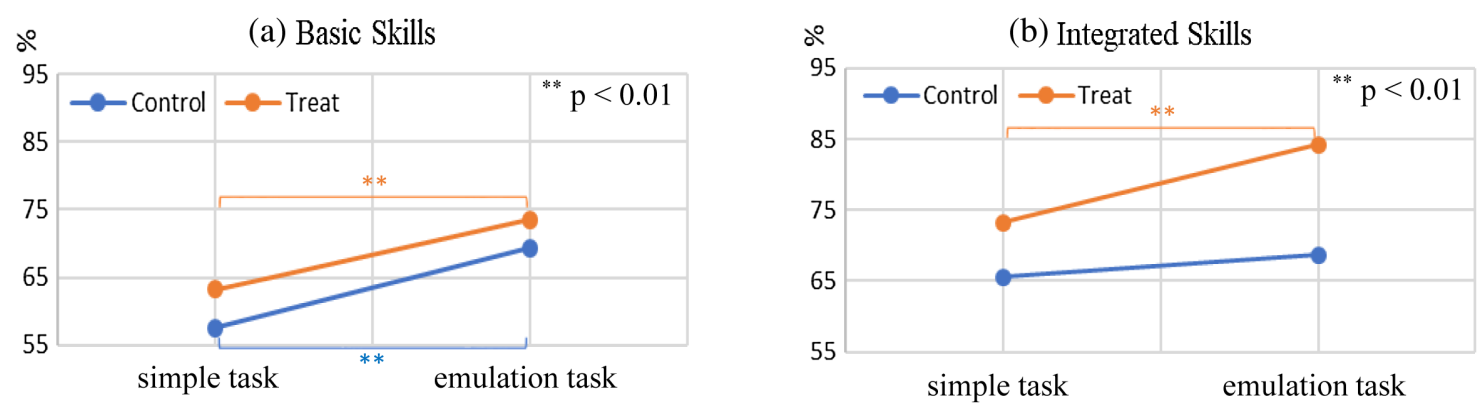

FIG. 6. Students' inquiry performance of (a) basic SPS, and (b) integrated SPS.

correctness percentage of SPS. For basic SPS [Fig. 6(a)], the repeated measured ANOVA shows a significant main effect for task complexity, $F(1,65)=29.61, p<0.001$, $\eta_{p}^{2}=0.31$. Both groups performed better on the second task. The effect size was large. However, there was no significant main effect between the two groups, $F(1,65)=3.31, p=0.07$, and no significant interaction effect, $F(1,65)=0.12, p=0.73$. Since the basic SPS supplemented no metacognitive scaffolding, the results implied that basic skills could be improved through repeated practice.

Students' inquiry performance on integrated SPS is illustrated in Fig. 6(b). The repeated measured ANOVA revealed that not only was there a significant main effect for task complexity, $F(1,65)=15.71, p<0.001, \eta_{p}^{2}=0.20$, but also a significant main effect between the groups, $F(1,65)=22.84, p<0.001, \eta_{p}^{2}=0.26$ and an interaction between the task complexity and the treatment of metacognitive scaffolding, $F(1,65)=4.89, \quad p=0.03$, $\eta_{p}^{2}=0.07$. The results showed that the integrated SPS of the treatment group were superior to those of the control group, especially on the emulation inquiry task.

\section{DISCUSSION}

In investigating the first research question, it was found that simulation-based inquiry could help students gain a deeper understanding of optics as well as better judgments of their understanding, regardless of metacognitive scaffolding. IBL with simulations can transform abstract constructs into perceptible representations and promote students' understanding. The effectiveness of simulationbased inquiry on students' conceptual understanding is consistent with those reported in previous studies $[69,70]$. Compared with the previous research, we also observed that the learning approach can reduce students' confidence bias of conceptual understanding. The more likely explanation is that IBL can give students an opportunity to assess their understandings based on the evidence presented in the experimental outcomes. As a result, they had a more accurate estimate of their conceptual understanding. Simply put, the positive effects were due to the nature of inquiry learning. The metacognitive scaffolding had no positive effects on learning optics concepts.

Research question 2 examined the effects of metacognitive scaffolding on students' integrated SPS and confidence judgments on integrated SPS. The results showed that IBL integrated with metacognitive scaffolding benefited students' integrated SPS and metacognitive monitoring of integrated SPS more than the IBL-alone approach. Metacognitive scaffolding could assist students with monitoring the data-analysis process and with making appropriate inferences. Consequently, the introduction of metacognitive scaffolding could enhance the effectiveness of IBL in terms of SPS. The effects were large. Theoretically, IBL should cultivate students' SPS [71]. However, the current study revealed that students did not learn integrated SPS significantly by doing inquiry. The metacognitive scaffolding could make explicit the learning of SPS to students and thus improve the SPS learning.

Research question 3 explored the role of metacognitive scaffolding in inquiry tasks with different degrees of complexity. Regarding basic SPS, the students performed better in the second (emulation) task than in the first (simple) task. The results showed that successful mastery of basic SPS might be mainly due to practice. For integrated SPS, they were facilitated by metacognitive scaffolding, especially on the emulation inquiry. An authentic inquiry is a complex problem-solving process and requires various

TABLE VI. Results of the correctness percentage of SPS in two inquiry tasks.

\begin{tabular}{lcccccc}
\hline \hline & & \multicolumn{2}{c}{ Basic SPS } & & \multicolumn{2}{c}{ Integrated SPS } \\
\cline { 3 - 4 } \cline { 6 - 7 } Group & $n$ & Simple task $M(S D)$ & Emulation task $M(S D)$ & & Simple task $M(S D)$ & Emulation task $M(S D)$ \\
\hline Treatment & 33 & $63.18(9.75)$ & $73.59(19.16)$ & & $73.18(12.74)$ & $84.17(11.53)$ \\
Control & 34 & $57.50(11.37)$ & $69.33(13.83)$ & & $65.59(12.54)$ & $68.71(12.24)$ \\
\hline \hline
\end{tabular}


integrated SPS [31,72]. The use of metacognitive strategies is critical to facilitate learning about complex systems [73]. Since there are no standard pathways in authentic inquiry contexts, metacognitive scaffolding assists students in monitoring and evaluating their use of cognitive strategies and justifying when and why to move on to another inquiry phase. More specifically, the metacognitive scaffolding becomes more important as the inquiry task becomes more complex.

Even though the experiments were positive and significantly improved simulation-based inquiry learning, the study has some limitations. First, the sample in the study was small, and so the generalization of the results might be limited. Future research should consider including more participants to raise the power of the research design. Second, the findings showed that the metacognitive scaffolding may have no effect on concept learning. In view of the relatively high intrinsic cognitive load of the complexity of IBL, the cognitive load associated with metacognitive scaffolding is crucial. Thus, students' prior knowledge and ability of metacognition should be considered while the aforementioned metacognitive prompts are used as scaffolding. The study did not assess students' cognitive load. The metacognitive scaffolding may have no effect on conceptual understanding due to cognitive overload. Future work is needed to clarify this important issue.

\section{CONCLUSIONS AND IMPLICATIONS}

This study concluded that simulation-based inquiry alone could achieve the purpose of conceptual understanding to a great extent. Students' confidence judgments on their conceptual understanding are also not affected by metacognitive scaffolding. Nevertheless, another important learning goal of IBL, namely, SPS, depends on the provision of the metacognitive scaffolding. Even though the basic SPS could be learnt by doing, as indicated by the better performance on the worksheet of the second task, the integrated SPS could be significantly improved with the help of the metacognitive scaffolding. Moreover, the more complex the task, the more effective the metacognitive scaffolding functions. This could be a result of learners' needs. They might not feel the need for extra help with a simple task. Alternatively, the scaffolding might work better after repeated use. We are hopeful that future research will provide more detailed results.

The findings of this study have important implications for the implementation of metacognitive strategies. The explicit metacognitive prompts we designed in the simulation-based inquiry could be applied to the analysis and conclusion phases in various inquiry activities due to the fact that the metacognitive scaffolding is not task specific. The task-general and easy to use features add practical values in school settings. Additionally, these metacognitive prompts serve as immediate feedback associated with the improvement of integrated SPS on students' inquiry performance. Similarly, based on the pre- and post integrated SPS tests, students' integrated SPS as well as the associated confidence judgment in the treatment group, but not in the control group, significantly increased. This finding implied that the improvement of integrated SPS not only occurs in practical work with metacognitive scaffolding, but also in the test without any scaffolding. Most simply put, the acquisition of SPS could be transferred to different contexts.

\section{ACKNOWLEDGMENTS}

This study was conducted under the support from the Ministry of Science and Technology, Taiwan (Grants No. MOST 109-2511-H-003-029- and No. MOST 1082511-H-011-002-MY4).
[1] National Research Council, National Science Education Standards (National Academies Press, Washington, DC, 1996).

[2] National Research Council, Inquiry and the National Science Education Standards: A Guide for Teaching and Learning (National AcademiesPress, Washington, DC, 2000).

[3] National Research Council, A framework for K-12 Science Education: Practices, Crosscutting Concepts, and Core Ideas (National Academies Press, Washington, DC, 2012).

[4] E. M. Furtak and W. R. Penuel, Coming to terms: Addressing the persistence of "hands-on" and other reform terminology in the era of science as practice, Sci. Educ. 103, 167 (2019).

[5] A. Hofstein and V. N. Lunetta, The laboratory in science education: Foundations for the twenty-first century, Sci. Educ. 88, 28 (2004).
[6] W. R. van Joolingen and Z. C. Zacharia, Developments in Inquiry Learning, Technology-Enhanced Learning (Springer, Dordrecht, 2009), pp. 21-37.

[7] G. Olympiou, Z. Zacharias, and T. Dejong, Making the invisible visible: Enhancing students' conceptual understanding by introducing representations of abstract objects in a simulation, Instr. Sci. 41, 575 (2013).

[8] L. M. Triona and D. Klahr, Point and click or grab and heft: Comparing the influence of physical and virtual instructional materials on elementary school students' ability to design experiments, Cognit. Instr. 21, 149 (2003).

[9] C. T. Wen, C. C. Liu, H. Y. Chang, C. J. Chang, M. H. Chang, S. H. F. Chiang, and F. K. Hwang, Students' guided inquiry with simulation and its relation to school science achievement and scientific literacy, Computers Educ. 149, 103830 (2020). 
[10] P. Colin and L. Viennot, Using two models in optics: Students' difficulties and suggestions for teaching, Am. J. Phys. 69, S36 (2001).

[11] I. Galili and A. Hazan, Learners' knowledge in optics: interpretation, structure and analysis, Int. J. Sci. Educ. 22, 57 (2000).

[12] M. S. Kocakulah and M. Kural, Investigation of conceptual change about double-slit interference in secondary school physics, Int. J. Environ. Sci. Educ. 5, 435 (2010).

[13] N. J. Selley, Children's ideas on light and vision, Int. J. Sci. Educ. 18, 713 (1996).

[14] B. S. Ambrose, P. S. Shaffer, R. N. Steinberg, and L. C. McDermott, An investigation of student understanding of single-slit diffraction and double-slit interference, Am. J. Phys. 67, 146 (1999).

[15] H. P. Chang, J. Y. Chen, C. J. Guo, C. C. Chen, C. Y. Chang, S. H. Lin, and C. C. Chen, Investigating primary and secondary students' learning of physics concepts in Taiwan, Int. J. Sci. Educ. 29, 465 (2007).

[16] S. K. Şengören, How do Turkish high school graduates use the wave theory of light to explain optics phenomena?, Phys. Educ. 45, 253 (2010).

[17] P. A. Kirschner, J. Sweller, and R. E. Clark, Why minimal guidance during instruction does not Work: An analysis of the failure of constructivist, discovery, problem-based, experiential, and inquiry-based teaching, Educ. Psychol. 41, 75 (2006).

[18] R. Azevedo, Understanding the complex nature of selfregulatory processes in learning with computer-based learning environments: An introduction, Metacognition Learn. 2, 57 (2007).

[19] J. A. Greene, D. C. Moos, R. Azevedo, and F. I. Winters, Exploring differences between gifted and grade-level students' use of self-regulatory learning processes with hypermedia, Computers Educ. 50, 1069 (2008).

[20] R. Azevedo, J. G. Cromley, F. I. Winters, D. C. Moos, and J. A. Greene, Adaptive human scaffolding facilitates adolescents' self-regulated learning with hypermedia, Instr. Sci. 33, 381 (2005).

[21] M. C. Kim and M. J. Hannafin, Scaffolding problem solving in technology-enhanced learning environments (TELEs): Bridging research and theory with practice, Computers Educ. 56, 403 (2011).

[22] C. Quintana, M. Zhang, and J. Krajcik, A framework for supporting metacognitive aspects of online inquiry through software-based scaffolding, Educ. Psychol. 40, 235 (2005).

[23] M. J. Padilla, The science process skills, NARST Research Matters, Occasional Publications to the Science Teacher, 1-2 (1987).

[24] P. N. Brotherton and P. F. Preece, Science process skills: Their nature and interrelationships, Res. Sci. Technol. Educ. 13, 5 (1995).

[25] E. Adadan, Analyzing the role of metacognitive awareness in preservice chemistry teachers' understanding of gas behavior in a multirepresentational instruction setting, J. Res. Sci. Teach. 57, 253 (2020).

[26] C. L. Lai, G. J. Hwang, and Y.H. Tu, The effects of computer-supported self-regulation in science inquiry on learning outcomes, learning processes, and self-efficacy, Educ. Technol. Res. Dev. 66, 863 (2018).
[27] W. X. Zhang, Y. S. Hsu, C. Y. Wang, and Y. T. Ho, Exploring the impacts of cognitive and metacognitive prompting on students' scientific inquiry practices within an e-learning environment, Int. J. Sci. Educ. 37, 529 (2015).

[28] Ministry of Education, Government of Taiwan, Curriculum Guidelines of 12-Year Basic Education, Accessed Nov 2018. https://www.naer.edu.tw/ezfiles/0/1000/attach/63/ pta_18538_240851_60502.pdf, 2018.

[29] E. Miller, E. Manz, R. Russ, D. Stroupe, and L. Berland, Addressing the epistemic elephant in the room: Epistemic agency and the next generation science standards, J. Res. Sci. Teach. 55, 1053 (2018).

[30] B. Y. White and J. R. Frederiksen, Inquiry, modeling, and metacognition: Making science accessible to all students, Cognit. Instr. 16, 3 (1998).

[31] J. Krajcik, P. C. Blumenfeld, R. W. Marx, K. M. Bass, J. Fredricks, and E. Soloway, Inquiry in project-based science classrooms: Initial attempts by middle school students, J. Learn. Sci. 7, 313 (1998).

[32] M. Pedaste, M. Mäeots, L. A. Siiman, T. De Jong, S. A. Van Riesen, E. T. Kamp, and E. Tsourlidaki, Phases of inquiry-based learning: Definitions and the inquiry cycle, Educ. Res. Rev. 14, 47 (2015).

[33] S. Rönnebeck, S. Bernholt, and M. Ropohl, Searching for a common ground-A literature review of empirical research on scientific inquiry activities, Studies Sci. Educ. 52, 161 (2016).

[34] S. Larkin, Metacognition in Young Children (Routledge New York, NY, 2009).

[35] A. Zohar and S. Barzilai, A review of research on metacognition in science education: Current and future directions, Studies Sci. Educ. 49, 121 (2013).

[36] M. Zion and R. Mendelovici, Moving from structured to open inquiry: Challenges and limits, Sci. Educ. Int. 23, 383 (2012).

[37] H. Jeong, N. B. Songer, and S. Y. Lee, Evidentiary competence: sixth graders' understanding for gathering and interpreting evidence in scientific investigations, Res. Sci. Educ. 37, 75 (2007).

[38] C. A. Chinn and W. F. Brewer, The role of anomalous data in knowledge acquisition: A theoretical framework and implications for science instruction, Rev. Educ. Res. 63, 1 (1993).

[39] D. Kuhn, M. Garcia-Mila, A. Zohar, and C. Andersen, Strategies of knowledge acquisition, Monographs Soc. Res. Child Develop. 60, 1 (1995).

[40] T. de Jong and W. R. Van Joolingen, Scientific discovery learning with computer simulations of conceptual domains, Rev. Educ. Res. 68, 179 (1998).

[41] J. van der Meij and T. de Jong, Supporting students' learning with multiple representations in a dynamic simulation-based learning environment, Learning Instr. 16, 199 (2006).

[42] G. Schraw, Promoting general metacognitive awareness, Instr. Sci. 26, 113 (1998).

[43] S. Manlove, A. W. Lazonder, and T. de Jong, Regulative support for collaborative scientific inquiry learning, J. Comput. Assist. Learn. 22, 87 (2006).

[44] P. A. Ertmer and T. J. Newby, The expert learner: Strategic, self-regulated, and reflective, Instr. Sci. 24, 1 (1996). 
[45] L. Stankov, J. Lee, W. Luo, and D. J. Hogan, Confidence: A better predictor of academic achievement than selfefficacy, self-concept and anxiety?, Learning Indiv. Diff. 22, 747 (2012).

[46] R. Sheldrake, Students' intentions towards studying science at upper-secondary school: the differential effects of under-confidence and over-confidence, Int. J. Sci. Educ. 38, 1256 (2016).

[47] J. Dunlosky and K. A. Rawson, Overconfidence produces underachievement: Inaccurate self evaluations undermine students' learning and retention, Learning Instr. 22, 271 (2012).

[48] P. S. Chang, S. H. Lee, and M. L. Wen, Metacognitive inquiry activities for instructing the central dogma concept:'button code'and 'beaded bracelet making', J. Biol. Educ. 54, 47 (2020).

[49] See Supplemental Material at http://link.aps.org/ supplemental/10.1103/PhysRevPhysEducRes.17.020108

for (a) optics conceptual test (chinese version) and (b) integrated science process skills test (chinese version).

[50] Y. Kutluay, Diagnosis of eleventh grade students' misconceptions about geometric optic by a three-tier test, master's thesis, Middle East Technical University, Ankara, Turkey, 2005.

[51] G. Tural, Cross-grade comparison of students' conceptual understanding with lenses in geometric optics, Sci. Educ. Int. 26, 325 (2015).

[52] K. S. Taber, The use of Cronbach's alpha when developing and reporting research instruments in science education, Res. Sci. Educ. 48, 1273 (2018).

[53] P. Turiman, J. Omar, A. M. Daud, and K. Osman, Fostering the 21 st century skills through scientific literacy and science process skills, Procedia-Social Behav. Sci. 59, 110 (2012).

[54] R. R. Wilke and W. J. Straits, Practical advice for teaching inquiry- based science process skills in biological sciences, Am. Biol. Teach. 67, 534 (2005).

[55] Z. Chen and D. Klahr, All other things being equal: Acquisition and transfer of the control of variables strategy, Child Development 70, 1098 (1999).

[56] D. Kuhn and M. Pease, What needs to develop in the development of inquiry skills?, Cognit. Instr. 26, 512 (2008).

[57] N. Glazer, Challenges with graph interpretation: A review of the literature, Studies Sci. Educ. 47, 183 (2011).

[58] N. Destan and C. M. Roebers, What are the metacognitive costs of young children's overconfidence?, Metacogn. Learn. 10, 347 (2015).

[59] S. Kleitman and T. Moscrop, Self-confidence and academic achievements in primary-school children: Their relationships and links to parental bonds, intelligence, age, and gender, in Trends and Prospects in Metacognition Research (Springer, Boston, MA 2010). pp. 293-326
[60] R. H. Maki, M. Shields, A. E. Wheeler, and T. L. Zacchilli, Individual differences in absolute and relative metacomprehension accuracy, J. Educ. Psychol. 97, 723 (2005).

[61] P. M. Kruit, R. J. Oostdam, E. van den Berg, and J. A. Schuitema, Assessing students' ability in performing scientific inquiry: instruments for measuring science skills in primary education, Res. Sci. Technol. Educ. 36, 413 (2018).

[62] C. Y. Kuo, H. K. Wu, T. H. Jen, and Y. S. Hsu, Development and validation of a multimedia-based assessment of scientific inquiry abilities, International Journal Sci. Educ. 37, 2326 (2015).

[63] C. J. Wenning, Assessing inquiry skills as a component of scientific literacy, J. Phys. Teach. Educ. Online 4, 21 (2007).

[64] H. S. Wang, S. Chen, and M. H. Yen, Facilitating understanding of image formation through the luminous ray model mediated by virtual simulation, Am. J. Phys. 86, 777 (2018).

[65] X. Gu, S. Chen, W. Zhu, and L. Lin, An intervention framework designed to develop the collaborative problemsolving skills of primary school students, Educational Technology Research and Development 63, 143 (2015).

[66] Y.S. Hsu, C. Y. Wang, and W. X. Zhang, Supporting technology-enhanced inquiry through metacognitive and cognitive prompts: Sequential analysis of metacognitive actions in response to mixed prompts, Comput. Hum. Behav. 72, 701 (2017).

[67] E. E. Peters and A. Kitsantas, Self-regulation of student epistemic thinking in science: The role of metacognitive prompts, Educ. Psychol. 30, 27 (2010).

[68] M. A. Teichert, L. T. Tien, L. Dysleski, and D. Rickey, Thinking processes associated with undergraduate chemistry students' success at applying a molecular-level model in a new context, J. Chem. Educ. 94, 1195 (2017).

[69] S. Abdullah and A. Shariff, The effects of inquiry-based computer simulation with cooperative learning on scientific thinking and conceptual understanding of gas laws, Eurasia J. Math. Sci. Technol. Educ. 4, 387 (2008).

[70] Z. Zacharia and O. R. Anderson, The effects of an interactive computer-based simulation prior to performing a laboratory inquiry-based experiment on students' conceptual understanding of physics, Am. J. Phys. 71, 618 (2003).

[71] R. Ergül, Y. Şımşeklı, S. Çaliş, Z. Özdılek, Ş. Göçmençelebı, and M. Şanli, The effects of inquiry-based science teaching on elementary school students' science process skills and science attitudes, Bulgarian J. Sci. Educ Policy. 5, 48 (2011).

[72] M. Pedaste and T. Sarapuu, Developing an effective support system for inquiry learning in a web-based environment, J. Comput. Assist. Learn. 22, 47 (2006).

[73] C. E. Hmelo-Silver and R. Azevedo, Understanding complex systems: Some core challenges, J. Learn. Sci. 15, 53 (2006). 